\title{
Comparison of activities of daily living after osteoporotic hip fracture surgery in patients admitted from home and from geriatric health service facilities
}

\author{
This article was published in the following Dove Press journal: \\ Clinical Interventions in Aging \\ 30 October 2014 \\ Number of times this article has been viewed
}

\author{
Akira Horikawa' \\ Naohisa Miyakoshi ${ }^{2}$ \\ Yoichi Shimada ${ }^{2}$ \\ Hiroyuki Kodama' \\ 'South Akita Orthopedic Clinic, \\ Katagami, ${ }^{2}$ Department of Orthopedic \\ Surgery, Akita University Graduate \\ School of Medicine, Akita, Japan
}

\begin{abstract}
With the population and proportion of the elderly increasing each year, difficulties with postoperative treatment outcomes after osteoporotic hip fracture are increasing. This study focused on activities of daily living (ADL) in patients who underwent surgery for hip fracture through an investigation of living arrangements, the presence of dementia, and other complications of aging. Information from 99 patients who lived either at home or in geriatric health service facilities was collected for this trial. Most patients were over 65 years of age and female, and about half of them had dementia. The postoperative ADL score (focusing on patients' walking ability) was significant for those living at home than for those living in facilities. In addition, patients with dementia were divided into the following two categories: an early-rising group, comprising patients who were able to use a wheelchair within 48 hours of their operation; and a late-rising group, who did not start using a wheelchair until more than 48 hours after surgery. The ADL scores for the two groups were compared. Although the preoperative ADL scores were not significantly different between the two groups, postoperative ADL scores were significantly higher in the early-rising group than in the late-rising group, especially in patients who had undergone hemiarthroplasty. These data suggest that ADL in dementia patients following hip fracture depends on the surgical procedure performed and whether they are late or early risers after surgery.
\end{abstract}

Keywords: delirium, dementia, rehabilitation, elderly

\section{Introduction}

Although there have been many studies investigating the treatment of osteoporotic hip fracture, few have reported on the outcome of activities of daily living (ADL) after fracture. ${ }^{1-6}$ Therefore, we identified patients who underwent a surgical procedure for femoral neck fracture, and assessed factors associated with their ADL score linked to walking ability after surgery for hip fracture. The patients were divided into two categories according to their lifestyle, and these were compared with their ADL levels. The patients were also examined for the presence of dementia, and those who had dementia were classified into two groups: an early-rising group, comprising patients who were able to use a wheelchair within 48 hours of their operation; and a late-rising group of patients who did not start using a wheelchair until more than 48 hours after surgery. The ADL scores in the two groups were compared. The data were analyzed looking at the combination of surgical procedure and dementia. The statistical analysis was performed using the Student's $t$-test or the chi-square test to evaluate the significance of differences; single-factor one-way analysis of variance and a post hoc
Correspondence: Akira Horikawa South Akita Orthopedic Clinic, Seiwakai, 96-2 Kaidousita, SyowaOokubo, Katagami 0I8-I40I, Japan $\mathrm{Tel}+8$ I I 88777 II 2

Fax $+8 I I 88777 \mid I 4$

Email akiraellen@me.com 
(Fisher's protected least significant difference) test were used to compare differences between the four study groups created based on a combination of the surgical procedure used and the presence of dementia.

\section{Patients and methods}

\section{Setting and participants}

One hundred and fifty consecutive patients who underwent a surgical procedure for a hip fracture at the South Akita Orthopedic Clinic in Katagami, Japan, the first author's institution, from 1999 to 2007 were enrolled in this trial. Of these patients, 51 who needed additional medical care or had psychological problems were excluded. The remaining 99 patients were eligible and completed the selection and classification process (Figure 1).

The presence of dementia was examined for using the Revised Hasegawa's dementia scale. ${ }^{7}$ The patient's living situation was classified as either independent (living in their own home) or institutionalized (living in a nursing home or a residential care home). Their ADL levels were as follows: patients in the home group were almost independent in their activities without aid, while the institutionalized group required assistance with three or more ADL, such as meals, clothing, and taking baths.

Hip fractures were classified by orthopedics, and the following three procedures were used: internal fixation using compression hip screws; intramedullary nailing fixation; and uncemented hemiarthroplasty. Hemiarthoplasty was carried out using the posterior approach. All patients received some physiotherapy after surgery and until discharge. Specifically, patients were encouraged to get into a wheelchair 1 day after their operation, and after a few days, they were assisted by physiotherapists in standing and taking a few steps using a walking table with personal support. The general routine was that patients admitted from either their homes or residential care facilities would be discharged as soon as they were medically stable.

\section{Measurements}

ADL scores based on walking ability were evaluated preoperatively and on discharge. The ADL score classified the

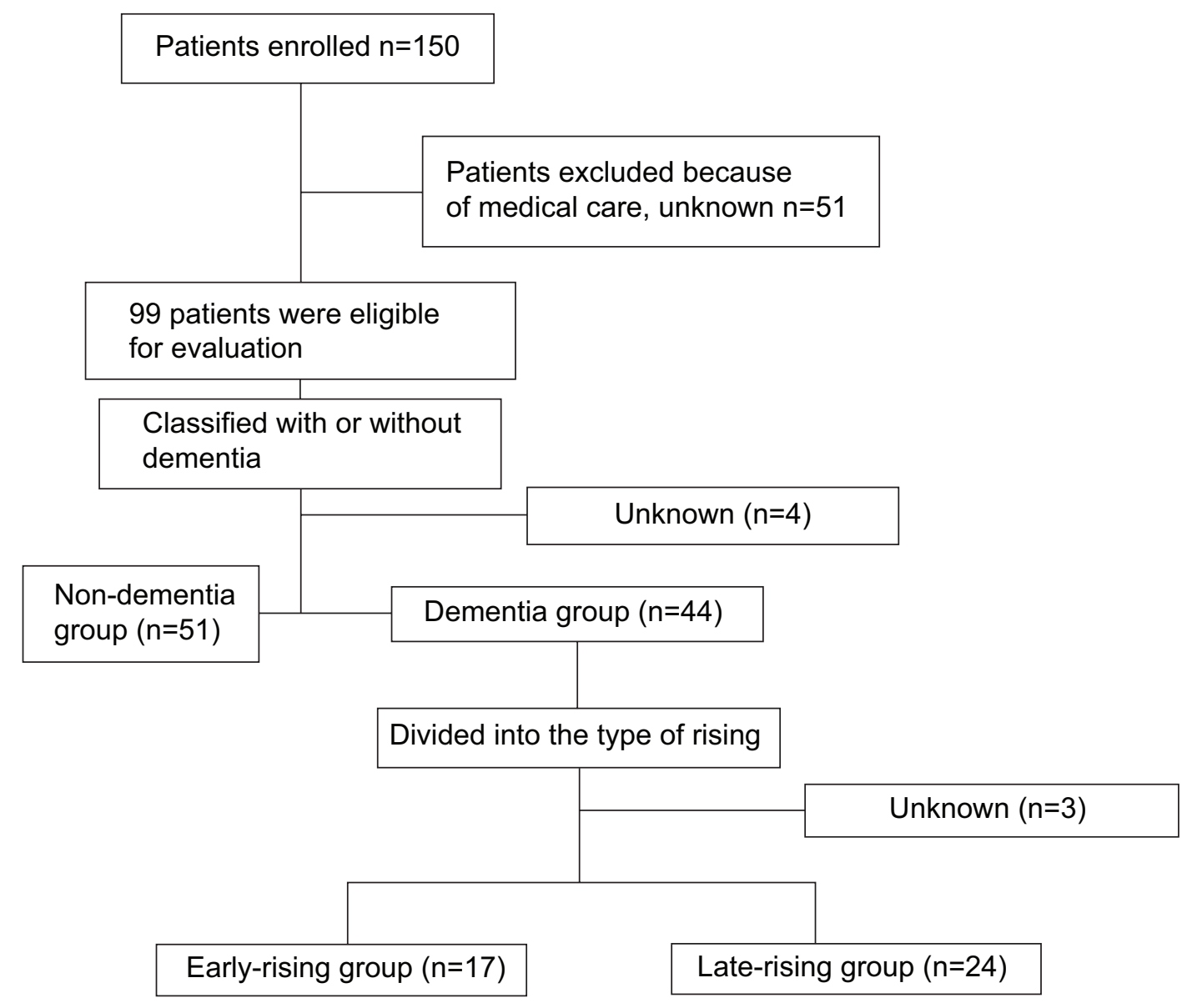

Figure I Study selection process.

Note: Data on age, sex, activities of daily living score, delirium, and length of stay were collected for all patients. 
physical activity of patients into the following five categories, ranging from 1 to 5 (Table 1): score 1, bed rest immobilization for 24 hours; score 2, use of a wheelchair with caregiver's aid; score 3, walking possible with a walking aid at home or in a geriatric health service facility; score 4, independent gait with a T-cane aid anytime and anywhere; and score 5, independent gait with no aid during daily activities. Patient follow-ups were performed in the admission and discharge phases by physiotherapists and caregivers. Patients were divided into an early-rising group and a late-rising group with regard to the starting phase of their rehabilitation. The early-rising group comprised patients who were motivated to get up and participate in physical rehabilitation by using a wheelchair within 48 hours of their operation, whereas the late-rising group comprised those who did not get up and use a wheelchair for more than 48 hours after surgery due to lack of motivation. Further, patients were classified according to their living situation as either independent (own home) or institutionalized (nursing home or residential care home). The ADL scores for the groups were then compared.

\section{Statistical analysis}

The statistical analysis was performed using Microsoft Office Excel and Statcel 3 (OMS Inc., Tokyo, Japan). The Student's $t$-test or the chi-square test were used to evaluate the significance of differences in dichotomous variables. Single-factor one-way analysis of variance and a post hoc (Fisher's protected least significant difference) test were used to compare differences between the four study groups created according to a combination of surgical procedure used and presence of dementia. Statistical results at the $P<0.05$ level were regarded as being statistically significant.

\section{Results}

The preoperative ADL scores in the early- and late-rising groups were not significantly different, but the postoperative ADL scores were significantly higher in the early-rising than in the late-rising group (Table 1). These results suggest that the early-rising group had a tendency toward a manic state, high activity, and an insensitivity to pain that made it possible to walk with an aid, whereas most of the late-rising group had delirium, depression, and low activity that forced them to use a wheelchair. No significant differences were observed in age, sex, and length of stay between the groups.

The preoperative and postoperative ADL scores were significantly higher in the home group, and the group in geriatric health service facilities had higher proportions of dementia and late-rising patients. No significant differences were seen in age, proportion of early-rising patients, or length of stay (Table 2). ADL scores were not different between the internal fixation and hemiarthroplasty groups (Table 3).

No significant differences were evident between the groups according to surgical procedure performed or the presence of dementia (Figure 2), but a significant difference was observed in ADL scores between the hemiarthroplasty group without dementia and the other groups (Figure 3).

\section{Discussion}

Itimura and $\mathrm{Ishi}^{8}$ suggested that patients with a hip fracture who lived in their own homes had a relatively better prognosis for ADL than those who lived in geriatric health service facilities postoperatively, and the present study supports this claim. The present study found that the ADL score was slightly higher for the home group than for the group living in geriatric health service facilities, while no significant difference was found in the number of patients with dementia. On the other hand, more patients in the geriatric health service facilities group than in the home group were late risers. This suggests that ADL after surgery for hip fracture depends on the type of dementia and is linked to rising time.

Although outcomes of hip fracture have been reported, the methodological quality of these studies was poor. ${ }^{9,10}$ Ingemarsson ${ }^{11}$ and Al-Ani et al ${ }^{12}$ noted that discharge to rehabilitation units and walking ability were associated with preserved walking ability and ADL in cognitively impaired patients with hip fractures, while Muir and Johannes ${ }^{13}$ recommended

Table I Comparisons of variables by time of rising

\begin{tabular}{|c|c|c|c|}
\hline & Early-rising group $(n=17)$ & Late-rising group $(n=24)$ & $P$-value \\
\hline Age, years & $83.5 \pm 4.1$ & $80.6 \pm 8.5$ & $0.196^{\mathrm{a}}$ \\
\hline Men/women (n) & $3 / 14$ & $3 / 21$ & $0.646^{\mathrm{a}}$ \\
\hline Preoperative ADL score & $4.4 \pm 0.8$ & $3.0 \pm 0.8$ & $0.079^{a}$ \\
\hline Postoperative ADL score & $3.0 \pm 1.4$ & $2.1 \pm 0.4$ & $<0.001^{a}$ \\
\hline Delirium & 4 & 16 & $0.006^{b}$ \\
\hline Length of stay (days) & $34.2 \pm 31.4$ & $48.9 \pm 38.9$ & $0.25 \mathrm{I}^{\mathrm{b}}$ \\
\hline
\end{tabular}

Notes: aStudent's $t$-test; ${ }^{b} \chi^{2}$ test.

Abbreviations: ADL, activities of daily living; $n$, number. 
Table 2 Comparisons of variables by living situation

\begin{tabular}{llll}
\hline & Home group $(\mathbf{n}=\mathbf{5 7})$ & Geriatric health service group $(\mathbf{n}=\mathbf{3 8})$ & $P$-value \\
\hline Age, years & $66.9 \pm 7.9$ & $74.8 \pm 6.4$ & $0.200^{\mathrm{a}}$ \\
Preoperative ADL score & $4.5(\mathrm{n}=57)$ & $3.9(\mathrm{n}=38)$ & $0.038^{\mathrm{a}}$ \\
Postoperative ADL score & $3.7(\mathrm{n}=24)$ & $2.3(\mathrm{n}=43)$ & $<\left.0.00\right|^{\mathrm{a}}$ \\
Dementia & 18 & 24 & $0.002^{\mathrm{b}}$ \\
Early-rising & 10 & 7 & $0.822^{\mathrm{b}}$ \\
Late-rising & 8 & 17 & $0.002^{\mathrm{b}}$ \\
Length of stay (days) & $52.9 \pm 25.4$ & $54.2 \pm 63.5$ & $0.902^{\mathrm{a}}$ \\
\hline
\end{tabular}

Notes: ${ }^{a}$ Student's $t$-test; ${ }^{b} \chi^{2}$ test.

Abbreviation: ADL, activities of daily living.

that intensive inpatient rehabilitation after surgical repair of a hip fracture may be able to achieve benefits in physical function for cognitively impaired patients that are comparable with those for cognitively intact patients.

The present cases showed no correlation between ADL score and preserved walking ability. Nevertheless, Lundström et $\mathrm{al}^{14}$ suggested that a large proportion of patients who are delirious when treated for a hip fracture develop dementia and have a higher mortality rate than those without delirium. The present results were similar in the present cases, and the mortality rate was able to be substituted for walking ability.

Furthermore, most patients in the late-rising group had delirium and a poor ADL score after their operation. Taking these facts into consideration, this study focused on the theory that large numbers of dementia patients who are delirious when treated for a hip fracture have worse ADL scores than those who are not delirious. That means that dementia patients with delirium are less likely to regain their walking ability than those who do not have delirium after hip fracture surgery. Lundström et $\mathrm{al}^{14}$ suggested that patients with hip fractures who were delirious postoperatively had an increased risk of dementia, and Olofsson et $\mathrm{al}^{15}$ mentioned that those who were delirious postoperatively had a tendency towards decreased ability to perform ADL. The reason why patients with a femoral neck fracture who were delirious had poorer ADL scores on admission or discharge and a greater risk of developing dementia was thought to be decreased systolic blood pressure that might have caused cerebral hypoxia after surgery. ${ }^{16}$ Consequently, more patients from geriatric health service facilities had reduced walking ability post-fracture than those living at home.

Table 3 Comparisons of variables by surgical procedure

\begin{tabular}{|c|c|c|c|}
\hline ADL score & $\begin{array}{l}\text { Internal fixation } \\
(n=59)\end{array}$ & $\begin{array}{l}\text { Hemiarthroplasty } \\
(n=36)\end{array}$ & $P$-value \\
\hline Preoperative & $4.3 \pm 1.1$ & $4.4 \pm 0.9$ & $0.720^{\mathrm{a}}$ \\
\hline Postoperative & $2.9 \pm 0.9$ & $3.1 \pm 1.1$ & $0.602^{\mathrm{a}}$ \\
\hline
\end{tabular}

Note: aStudent's t-test.

Abbreviation: ADL, activities of daily living.
Some research has shown that life expectancy is better after internal fixation of hip fracture than after hemiarthroplasty, ${ }^{17,18}$ whereas other reports implied no differences between these surgical techniques. ${ }^{19,20}$ The present results show significant differences in ADL scores between the hemiarthroplasty group with dementia and the other groups. Thus, ADL after femoral neck fracture depends not only on the surgical procedure used, but also on other complications such as dementia.

In summary, the present study focused on factors associated with the ADL score linked to walking ability after surgery for femoral neck fracture, and patients were divided into two categories based on when they started rehabilitation (an early-rising group and a late-rising group). Preoperative ADL scores were not significantly different between the two groups, but postoperative ADL scores were significantly higher for the early-rising group than for the late-rising group. These results indicate that patients who use a wheelchair early have a tendency to react better to physical therapy. Further, the patients in this study were classified according to their residence, ie, at home or in geriatric health service facilities,

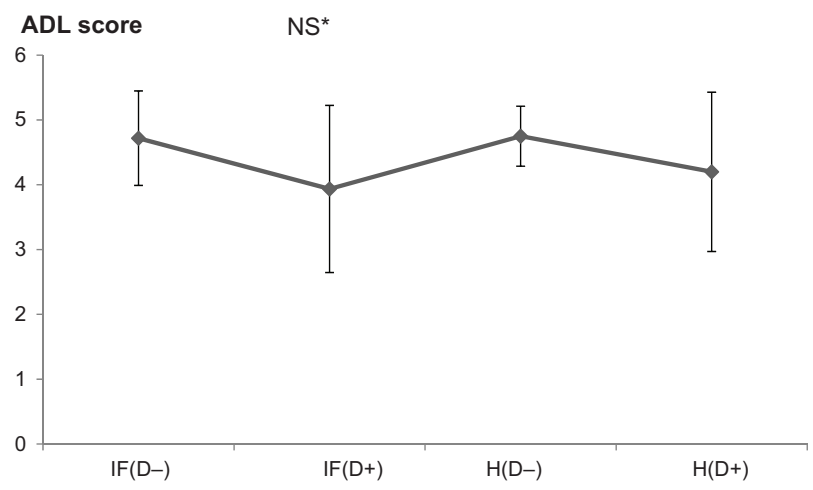

Figure 2 No significant differences are observed among the groups in the preoperative phase.

Note: $* P>0.05$.

Abbreviations: $A D L$, activities of daily living; IF(D-), internal fixation without dementia, $n=3 I ; I F(D+)$, internal fixation with dementia, $n=32 ; H(D-)$, hemiarthroplasty without dementia, $n=10 ; H(D+)$, hemiarthroplasty with dementia, $n=I 3 ; n$, number of patients; NS, not significant. 


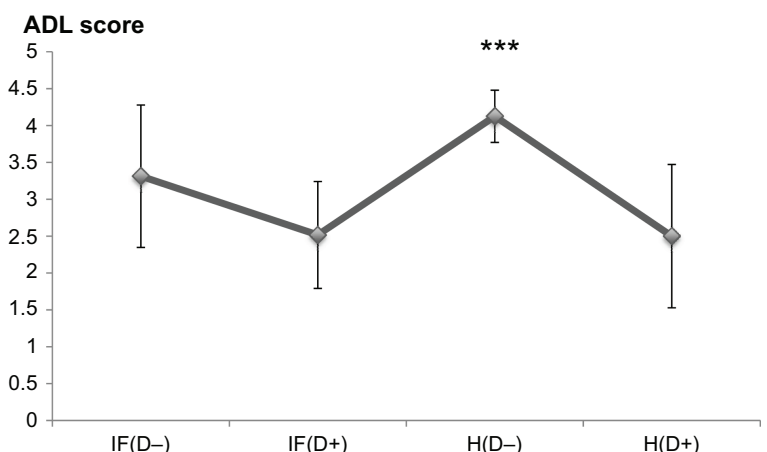

Figure 3 A significant difference is observed in ADL scores between the hemiarthroplasty group without dementia and the other groups in the postoperative phase.

Note: $* * * P<0.001$ (post hoc test).

Abbreviations: $A D L$, activities of daily living; IF(D-), internal fixation without dementia, $n=3$ I; IF(D+), internal fixation with dementia, $n=32 ; H(D-)$, hemiarthroplasty without dementia, $n=10 ; H(D+)$, hemiarthroplasty with dementia, $n=13 ; n$, number of patients.

and their ADL scores were compared. The average ADL score was significantly higher in the home group than in the geriatric health service facilities group. This means that patients who lived in their own home had an easier time recovering after femoral neck fracture surgery. The present report suggests that ADL following surgery for hip fracture depends on the type of dementia that accompanies delirium.

\section{Acknowledgments}

This study was supported by the South Akita Orthopedic Clinic and the Akita University Graduate School of Medicine. The authors thank the patients who participated in this trial, as well as the staff, including nurses, caregivers, and physiotherapists, for supporting our research.

\section{Disclosure}

The authors report no conflicts of interest in this work.

\section{References}

1. Stenvall M, Berggren M, Lundström M, Gustafson Y, Olofsson B. A multidisciplinary intervention program improved the outcome after hip fracture for people with dementia - subgroup analyses of a randomized controlled trial. Arch Gerontol Geriatr. 2012;54(3):e284-e289.

2. Lin PC, Chang SY. Functional recovery among elderly people one year after hip fracture surgery. $J$ Nurs Res. 2004;12(1):72-82.
3. Sakamoto K, Nakamura T, Hagino H, Endo N, Mori S. Report on the Japanese Orthopedic Association's 3-year project observing hip fractures at fixed-point hospitals. J Orthop Sci. 2006;11(2):127-134.

4. Ekström W, Németh G, Samnegård E, Dalen N, Tidemark J. Quality of life after a subtrochanteric fracture: a prospective cohort study on 87 elderly patients. Injury. 2009;40(4):371-376.

5. Cree AK, Nade S. How to predict return to the community after fractured proximal femur in the elderly. Aust N Z Surg. 1999;69(10):723-725.

6. Tidermark J. Quality of life and femoral neck fractures. Acta Orthop Scand Suppl. 2003;74(309):1-42.

7. Osafune M, Deguchi K, Abe K. [Ideal combination of dementia screening tests]. Nihon Ronen Igakkai Zasshi. 2014;51(2):178-183. Japanese.

8. Itimura K, Ishi S. [Factors that influence the ability to walk in elderly patients after femoral neck fracture treatment after discharge: logistic regression analysis]. Seikeigeka. 2001;52:1340-1342. Japanese.

9. Simanski C, Bouillon B, Lefering R, Zumsande N, Tiling T. [What prognostic factors correlate with activities of daily living (Barthel Index) 1 year after para-articular hip fracture? A prospective observational study]. Unfallchirurg. 2002;105(2):99-107. German.

10. Tobu S, Noguchi M, Hashikawa T, Uozumi J. Risk factors of postoperative urinary retention after hip surgery for femoral neck fracture in elderly women. Geriatr Gerontol Int. 2014;14(3):636-639.

11. Ingemarsson AN. Walking ability and activity level after hip fracture in the elderly - a follow-up. J Rehabil Med. 2003;35(2):76-83.

12. Al-Ani AN, Flodin L, Söderqvist A, et al. Does rehabilitation matter in patients with femoral neck fracture and cognitive impairment? A prospective study of 246 patients. Arch Phys Med Rehabil. 2010; 91(1):51-57.

13. Muir S, Yohannes A. The impact of cognitive impairment on rehabilitation outcomes in elderly patients admitted with a femoral neck fracture: a systematic review. J Geriatr Phys Ther. 2009;32(1):24-32.

14. Lundström M, Edlund A, Bucht G, Karlsson S, Gustafson Y. Dementia after delirium in patients with femoral neck fractures. $J$ Am Geriatr Soc. 2003;51(7):1002-1006.

15. Olofsson B, Lundström M, Borssén B, Nyberg L, Gustafson Y. Delirium is associated with poor rehabilitation outcome in elderly patients treated for femoral neck fractures. Scand J Caring Sci. 2005;19(2):119-127.

16. Edlund A, Lundstrom M, Brannstrom B. Delirium before and after operation for femoral neck fracture. J Am Geriatr Soc. 2001;49(10): $1335-1340$.

17. Takashi M. [Guideline of treatment of femoral neck fracture]. Rev. 2011;2:78-80. Japanese.

18. Tjiang GC, Koppert KL, Hermans ET, Poelhekke LM, Dawson I. [Replacement of the femoral head due to fracture of the hip: prognostic factors for the duration of hospitalisation, institutionalisation and mortality]. Ned Tjidschr Geneeskd. 2003;147(50):2483-2487. Dutch.

19. Stoen RO. Randomized trial of hemiarthroplasty versus internal fixation for femoral neck fracture: no differences at 6 years. Clin Orthop Relat Res. 2014;472(1):360-367.

20. Blomfeldt R, Törnkvist H, Ponzer S, Söderqvist A, Tidermark J. Internal fixation versus hemiarthroplasty for displaced fractures of the femoral neck in elderly patients with severe cognitive impairment. J Bone Joint Surg Br. 2005;87(4):523-529.
Clinical Interventions in Aging

\section{Publish your work in this journal}

Clinical Interventions in Aging is an international, peer-reviewed journal focusing on evidence-based reports on the value or lack thereof of treatments intended to prevent or delay the onset of maladaptive correlates of aging in human beings. This journal is indexed on PubMed Central, MedLine,

\section{Dovepress}

CAS, Scopus and the Elsevier Bibliographic databases. The manuscript management system is completely online and includes a very quick and fair peer-review system, which is all easy to use. Visit http://www.dovepress. com/testimonials.php to read real quotes from published authors. 